\title{
Variability of climate, water and nitrogen status and its influence on vine phenology and grape composition inside a small winegrowing estate
}

\author{
Laure de Rességuier ${ }^{1}$, Renan Le Roux ${ }^{2}$, Théo Petitjean ${ }^{1}$, Séverine Mary ${ }^{3}$, Hervé Quénol ${ }^{2}$ and Cornelis van \\ Leeuwen $^{1}$ \\ ${ }^{1}$ EGFV, Bordeaux Sciences Agro, INRA, Univ. Bordeaux, ISVV, 33883 Villenave d'Ornon, France \\ ${ }^{2}$ LETG-RENNES, UMR 6554 CNRS, Université de Rennes 2, 35000 Rennes, France \\ ${ }^{3}$ Vitinnov, Bordeaux Sciences Agro, ISVV, 33175 Gradignan cedex, France
}

\begin{abstract}
Climate is a major terroir factor in viticulture. In winegrowing regions, climate is studied at an increasingly refined scale. Results from the Life ADVICLIM project show substantial spatial variability of temperatures inside the region of Saint-Emilion, Pomerol and surrounding appellations (Bordeaux, France). In this study we investigated climatic variability at an even more refined scale, inside an 11 ha estate located in Saint-Emilion with significant topographic variability, planted with Merlot and Cabernet franc. Elevation ranges from 34 to 81 meters. 31 temperature sensors were set-up in 2013 inside the canopy, taking into account all parameters linked to the topography. Spatial temperature variability and its influence on vine phenology and grape composition were investigated. Vine water and nitrogen status were also taken into account through $\delta^{13} \mathrm{C}$ and $\mathrm{N}$-tester measurements. Over the growing season (April 1 through September 30), spatial temperature variability was greater on minimum temperatures $\left(1.6^{\circ} \mathrm{C}\right)$ compared to maximum temperatures $\left(1.3^{\circ} \mathrm{C}\right)$. Spatial variability in minimum temperature was driven by elevation and slope. Further investigation is required for spatial variability in maximum temperature, which could not be explained by environmental co-variables. Temperature variability among vintages was driven by maximum temperature, while minimum temperature showed little variation from one year to another. The average Winkler Index measured in the canopy ranged from 1774 degree.days to 1978 degree.days. This spatial variability of 204 degree.days can induces potentially 20 days difference in maturity dates. The timing of flowering varied from one vintage to another but inside a given vintage spatial variability was small, and so was variability induced by the cultivar. Veraison dates were highly variable among vintages. Inside a given vintage, spatial variability and cultivar effect were significant. Berry weight was driven by vine water and nitrogen status. Berry malic acid content was impacted by temperature. Vine water and nitrogen status also influenced berry malic acid content. Berry sugar content depended mainly on vine nitrogen status. The grapevine variety influenced berry sugar and malic acid content, as well as berry mass.
\end{abstract}

\section{Introduction}

Environmental factors like climate, soil, topography, play an important role on vine development [1] and grape quality potential [2].

In this study, climate is analysed at very local scale in an estate of 11.2 ha located in a part of Bordeaux area defined by a pronounced relief and multiple exposures.

The distinctive feature of this study is the density of the temperature sensor network: 1 sensor for 0.4 ha which allows to characterize temperatures at the winegrowing estate scale. On each parcel equipped with a sensor, phenological stages were monitored as well as grape composition and vine water and nitrogen status.

The first objective of this study is to characterize the temperature variability inside a winegrowing estate and to define the environmental parameters that contribute to this spatial distribution. The other major objective is to analyse the parameters which impact vine development and grape composition. Beside temperatures, the combined effect of soil and climate was investigated through vine water and nitrogen status.

The result of this study allows winegrowers to better adapt plant material and vineyard management practices to terroir components, especially in a context of climate change.

\section{Materials and methods}

\subsection{Temperature network}

31 temperature sensors (Tinytag Talk2, Gemini Data Loggers, UK) have been set up at the beginning of 2013, to monitor temperatures on this estate of 11.2 ha with an altitudinal gradient of 50 meters (Figure 1). To choose the location of the sensors, a Digital Elevation Model was created and used to cover the environmental parameters: elevation, slope and exposures. 




Figure 1. Location of the temperature sensors projected on a Digital Elevation Model

The temperature sensors were installed on vine posts inside vineyard parcels and record both minimum and maximum hourly temperatures. Temperature sum base of $10^{\circ} \mathrm{C}$ was computed from 1 April through 31 October. Because temperatures were measure in the canopy and not in a classical weather station, this temperature sum is referred to as "Canopy Winkler Index".

\subsection{Ecophysiological measurements}

Ecophysiological measurements have been carried out to monitor vine development and grape composition on 31 blocks located near the temperature sensors. This property is mainly planted with Merlot and Cabernet franc. One block is composed of 20 successive vines. In this estate, some parcels contain mixed plantations of Merlot and Cabernet franc. When those two grape varieties are present in the same block, 10 vines per variety are observed.

Phenological stages (flowering and veraison) were monitored, and the specific day when 50 percent of vine organs reach stage "I" for flowering and stage " $\mathrm{M}$ " for veraison [3] are recorded.

Once a year, a maturity control is carried out for all the blocks at the same date. Each sample is composed of 60 berries. Berries were weighted and Reducing Sugars, Total Acitidy (TA), Malate (MAL) and $\mathrm{pH}$ were measured. In order to determine vine water status and vine nitrogen status, $\delta^{13} \mathrm{C}$ and Yeast Available Nitrogen (YAN) was measured $[4,5]$.

Vine nitrogen status was also assessed through N-tester measurements at veraison stage with 3 replicates per block [5].

\subsection{Statistical analyses}

The effects of environmental parameters (elevation, slope, exposure) on mean, minimum and maximum average daily temperatures and on Canopy Winkler Index were analyzed by using multiple linear regressions. The maturity parameters have been analysed by a linear mixed model [6] including minimum temperature, YAN, $\delta^{13} \mathrm{C}$ and grape variety as fixed effects. We considered "vintage" as a random effect to account for the repeated measurements conducted each year.

For creating the map of Canopy Winkler Index, a model based on a Support Vector Regression (SVR) was used [7].

\section{Results and discussion}

\subsection{Growing season temperature variability}

Figure 2 represents the daily mean, minimum and maximum temperatures during the growing season (April $1^{\text {st }}$ to September $30^{\text {th }}$ ) over the 5 years studied.
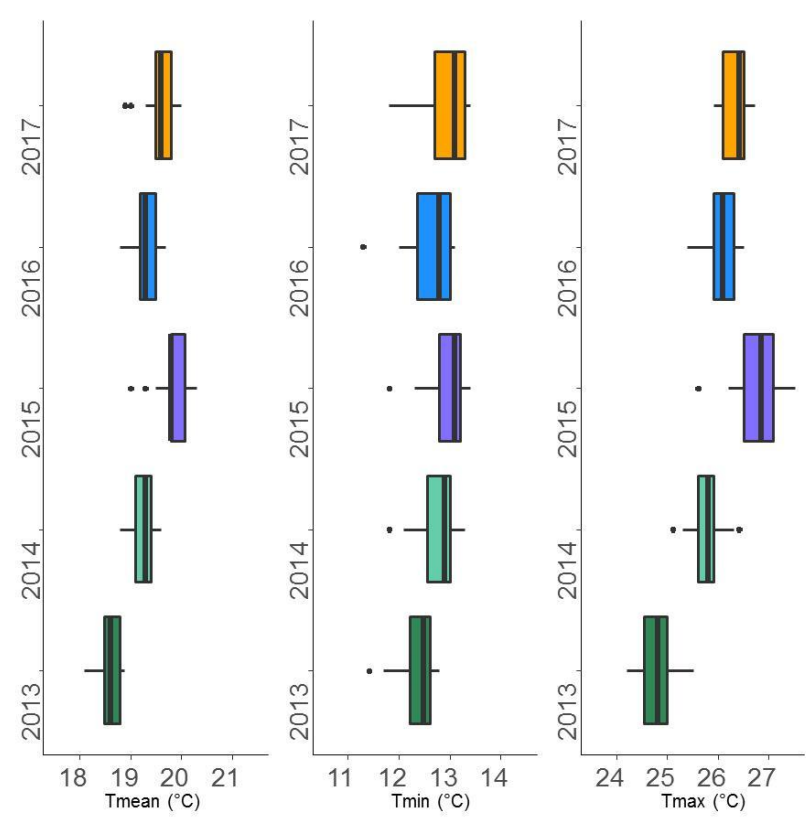

Figure 2. Boxplots on mean, minimum and maximum average daily temperatures over the growing season (from April $1^{\text {st }}$ to September $30^{\text {th }}$ )

A clear vintage effect is observed: 2015 is the warmest vintage and 2013 the coldest.

Inter annual variability is greater on mean and maximum temperatures than on minimum temperature which is more or less similar and constant each year. So the vintage effect is due to variations in maximum temperature which impact the mean temperature.

The range of temperatures between the coldest and the warmest sensor is greater for minimum temperatures $\left(1.6^{\circ} \mathrm{C}\right.$ in average on the 5 vintages) than for maximum temperatures $\left(1.3^{\circ} \mathrm{C}\right.$ in average $)$. For mean temperature there is a range of $1{ }^{\circ} \mathrm{C}$ ( 5 years average) between the coldest and the warmest sensor.

Statistical analysis (Table 1) show relationships between temperatures and topographic parameters. Minimum temperatures are driven by elevation and slope. At this local scale, the minimum temperature increases with elevation and slope. In 2017, there is also a relation with North/South exposure. South exposure is warmer than North exposure. 
For maximum temperature, no linear relationships were found between temperature and topographic variables. The variations of maximum temperature at this micro scale is more complexe than for minimum temperature, with certainly more thermic variations during the day but also from day to day.

As for minimum temperature the spatial distribution of mean temperature is explained by elevation and slope.

Table 1. Relationships between average temperatures during vegetative season and environmental covariables

\begin{tabular}{ccccccc}
\hline Year & $\begin{array}{c}\text { Temp growing } \\
\text { season }\end{array}$ & $\begin{array}{c}\text { variance (\%) } \\
\text { explain by } \\
\text { the model }\end{array}$ & Altitude & Slope & $\begin{array}{c}\text { N/S } \\
\text { exposure }\end{array}$ & $\begin{array}{c}\text { E/W } \\
\text { exposure }\end{array}$ \\
\hline \multirow{2}{*}{2013} & Tmin & 75 & $* * *$ & $* * *$ & $\mathrm{~ns}$ & $\mathrm{~ns}$ \\
& Tmax & 11 & $\mathrm{~ns}$ & $\mathrm{~ns}$ & $\mathrm{~ns}$ & $\mathrm{~ns}$ \\
$\mathbf{2 0 1 4}$ & Tmean & 39 & $*$ & $*$ & $\mathrm{~ns}$ & $\mathrm{~ns}$ \\
& Tmin & 82 & $* * *$ & $* * *$ & $\mathrm{~ns}$ & $\mathrm{~ns}$ \\
& Tmax & 22 & $*$ & $\mathrm{~ns}$ & $\mathrm{~ns}$ & $\mathrm{~ns}$ \\
$\mathbf{2 0 1 5}$ & Tmean & 34 & $*$ & $\mathrm{~ns}$ & $\mathrm{~ns}$ & $\mathrm{~ns}$ \\
& Tmin & 83 & $* * *$ & $* * *$ & $\mathrm{~ns}$ & $\mathrm{~ns}$ \\
& Tmax & 6 & $\mathrm{~ns}$ & $\mathrm{~ns}$ & $\mathrm{~ns}$ & $\mathrm{~ns}$ \\
& Tmean & 37 & $* *$ & $*$ & $\mathrm{~ns}$ & $\mathrm{~ns}$ \\
& Tmin & 78 & $* * *$ & $* *$ & $\mathrm{~ns}$ & $\mathrm{~ns}$ \\
& Tmax & 27 & $\mathrm{~ns}$ & $\mathrm{~ns}$ & $\mathrm{~ns}$ & $\mathrm{~ns}$ \\
& Tmean & 51 & $* * *$ & $* *$ & $\mathrm{~ns}$ & $\mathrm{~ns}$ \\
& Tmin & 87 & $* * *$ & $* * *$ & $*$ & $\mathrm{~ns}$ \\
\hline & Tmax & 30 & $\mathrm{~ns}$ & $\mathrm{~ns}$ & $\mathrm{~ns}$ & $\mathrm{~ns}$ \\
\hline
\end{tabular}

ns: not significant; $* * *$ significant at $p<0.001 ; * *$ significant at $p<0.01 ; *$ significant at $p<0.05$

\subsection{Canopy Winkler Index}

In order to improve the characterization of climate variability, the Winkler degree day summation [8], which is well adapted to study the influence of temperature on vine development, is used here. This index is based on the sum of temperatures above $10^{\circ} \mathrm{C}$, from April 1 st to October 31st. Because temperatures were measured inside the canopy, this index is referred to as Canopy Winkler Index.

Result shows that at this local scale, there is a variability of 204 degree.days on average over the 5 years studied between the coolest and the warmest sensor (Figure 3 ). Given this wide temperature range, maturity could be delayed by 20 days in the latest ripening parcels, compared to early ripening parcels.



Figure 3. Boxplots of Canopy Winkler Index from 2013 to 2017

The elevation, slope and North/South exposure are covariables that explain the distribution of Canopy Winkler Index (Figures 4). Canopy Winkler Index increase by 50 degree.days with an increase in elevation of 40 meters (Figure 4a) and with steep slopes (Figure 4b). South exposure is warmer than North exposure (Figure 4c) and there is no linear relationship with East/West exposure.

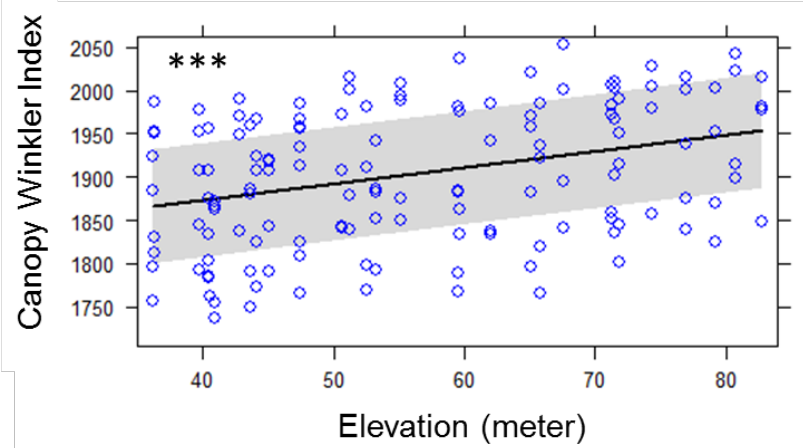

Figure 4a. Relationship between Canopy Winkler Index and elevation

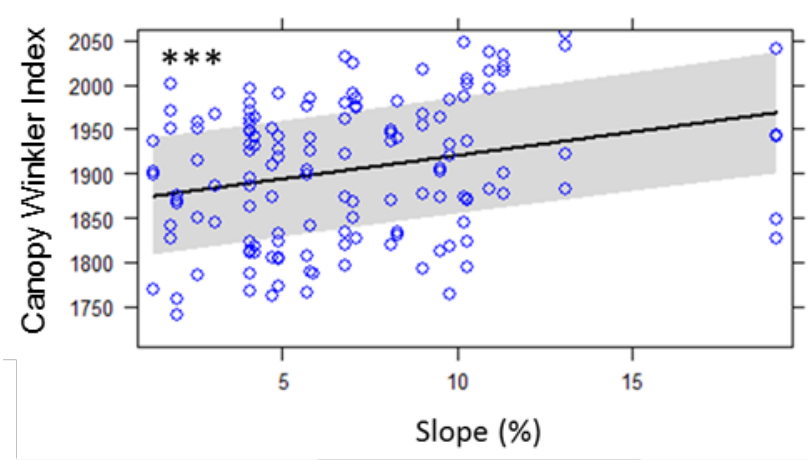

Figure 4b. Relationship between Canopy Winkler Index and slope 


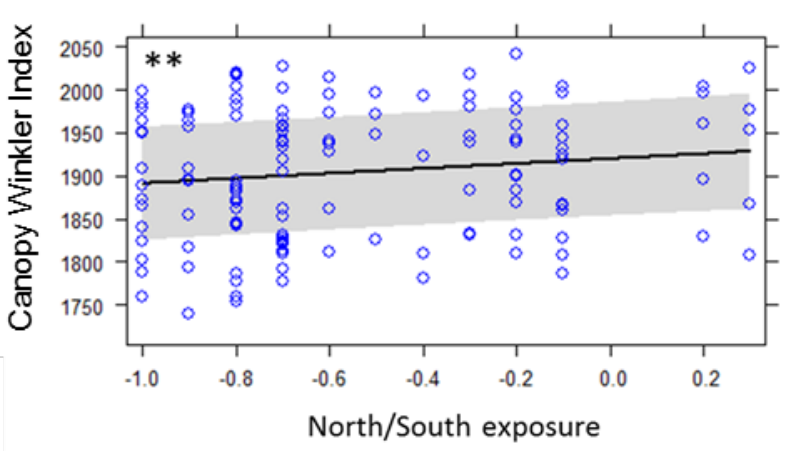

Figure 4c. Relationship between Canopy Winkler Index and North/South exposure

The map of average Canopy Winkler Index from 2013 to 2017 (Figure 5) shows that spatial distribution of the index is linked to the topography. The limestone plateau located at the top of the hill on the Western part of the estate and the East facing slopes are the warmest areas. The bottom of the valley is the coldest area. Cooler areas are also located on the West facing slopes.



Figure 5. Spatial distribution of Canopy Winkler Index (average 2013-2017)

\subsection{Phenology observations}

The phenology recordings of Merlot and Cabernet franc did not reveal significant differences between the grape varieties at flowering (Figure 6). The timing of flowering varied from one vintage to another but inside a given vintage variability was small.

For veraison a grape variety effect is observed, Merlot is more precocious. Amplitude of veraison dates vary with the vintage. It is on average greater for Cabernet franc.

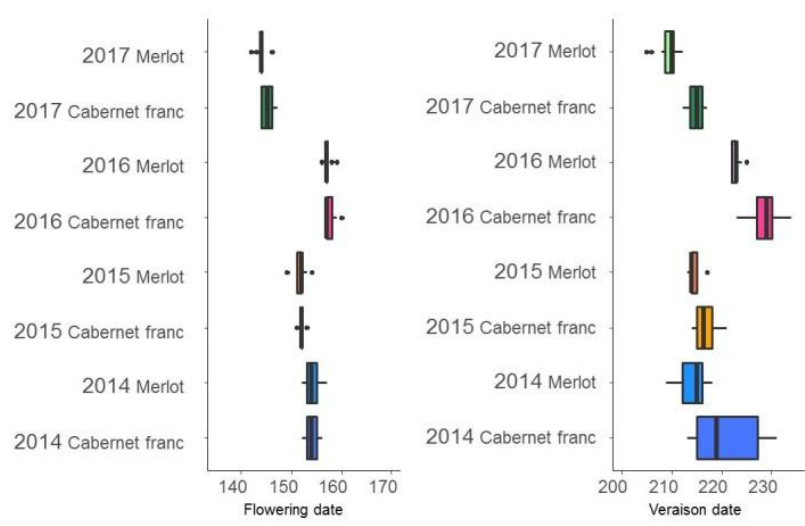

Figure 6. Boxplots of phenology observations from 2013 to 2017

\subsection{Relations between temperature, vine water status, vine nitrogen status and grape composition}

In order to investigate the relations between temperature, vine water status, vine nitrogen status, berry weight and grape composition, statistical analyses were carried out (Table 2).

For all parameters a grape variety effect is shown: Merlot has bigger berries and is earlier than Cabernet franc.

Berry weight is well explained by $\mathrm{YAN}, \delta^{13} \mathrm{C}$ and minimum temperature over growing season (Table 2) which is also linked with elevation and slope (Table 1). Berry weight decreases with the elevation of temperature and water deficit, and increases with YAN.

For grape sugar content there is a strong opposed link with YAN and a small link with temperature. Gape sugar content decreases with YAN, while Malate increases with YAN. Malate is also linked with $\delta^{13} \mathrm{C}$ and minimum temperature. The increase of water deficit and minimum temperature decrease berries malate concentration.

For the maturity indicator Sugar/TA, there is a strong effect of YAN. This indicator decreases with an increase of YAN. There is also a small relationship with $\delta^{13} \mathrm{C}$, the level of maturity increases with water deficit.

Table 2. Relationships between berry weight, Sugar and Malate with minimum temperature during the growing season, $\delta^{13} \mathrm{C}$, YAN and grape variety

\begin{tabular}{|c|c|c|c|c|}
\hline & $\begin{array}{c}\text { Tmin } \\
\text { Growing season }\end{array}$ & $\delta^{13} \mathrm{C}$ & YAN & $\begin{array}{l}\text { Grape } \\
\text { Variety }\end{array}$ \\
\hline $\begin{array}{l}\text { Berry } \\
\text { Weight }\end{array}$ & $\begin{array}{c}* * * \\
\text { Berry weight } \searrow \\
\text { when Tmin } \lambda\end{array}$ & $\begin{array}{c}* * * \\
\text { Berry weight } \searrow \\
\text { when } \delta^{13} C\end{array}$ & $\begin{array}{c}* * * \\
\text { Berry weight } \lambda \\
\text { when YAN } \lambda\end{array}$ & $\stackrel{*}{\mathrm{M}>\mathrm{CF}}$ \\
\hline Sugar & $\begin{array}{c}* \\
\text { Sugar } \lambda \\
\text { when Tmin } \lambda\end{array}$ & ns & $\begin{array}{c}* * * \\
\text { Sugar } \nearrow \\
\text { When YAN } y\end{array}$ & $\begin{array}{c}* * * \\
\mathrm{M}>\mathrm{CF}\end{array}$ \\
\hline Malate & $\begin{array}{c}\text { *** } \\
\text { Malate } \searrow \\
\text { when Tmin } \nearrow\end{array}$ & $\begin{array}{c}* * * \\
\text { Malate } \searrow \\
\text { when } \delta^{13} \mathrm{C} \nearrow\end{array}$ & $\begin{array}{c}* * \\
\text { Malate } \searrow \\
\text { When YAN } y\end{array}$ & $\begin{array}{c}* * * \\
\mathrm{M}<\mathrm{CF}\end{array}$ \\
\hline Sugar/TA & ns & $\begin{array}{c}* \\
\text { Sugar/TA } \nearrow \\
\text { when } \delta^{13} C \nearrow\end{array}$ & $\begin{array}{c}* * * \\
\text { Sugar/TA } \searrow \\
\text { when YAN } \nearrow\end{array}$ & $\stackrel{*}{M}>\mathrm{CF}$ \\
\hline
\end{tabular}

$n s:$ not significant; $* * *$ significant at $p<0.001$; ** significant at $p<0.01 ; *$ significant at $p<0.05$ 


\section{Conclusion}

This innovative study at this very local scale highlights the great temperature range that can be found in such a small territory with more than 200 degree.days of amplitude for Canopy Winkler Index between the coldest and the warmest sensors. For comparison, inside the region of Saint-Emilion, Pomerol and surrounding appellations which extends over a larger area (12200ha), 280 degree.days of amplitude is found for the same period [9].

Temperature variability among vintages was driven by maximum temperature, while minimum temperature showed small variation from one year to another. The great spatial variability of minimum temperature is driven by elevation and slope. But further investigation is required for spatial variability of maximum temperature, which could not be explained by these environmental variables.

The timing of flowering varied from one vintage to another but inside a given vintage spatial variability is small. Veraison dates were highly variable among vintages and inside a given vintage, spatial variability and cultivar effect were significant.

For maturity, berry weight is driven by vine water and nitrogen status and minimum temperature. There is a strong significant effect of nitrogen status and a smaller effect of minimum temperature on berry sugar content. Berry malic acid content is related to vine water status and minimum temperature with lower impact of vine nitrogen status.

The results of this study will allow winegrowers to better adapt plant material and vineyard management practices to terroir components which is of particular importance in a context of climate change.

\section{Acknowledgements}

This study has been carried out with financial support from the Conseil Interprofessionnel du Vin de Bordeaux, the European Union Life Adviclim project (LIFE 13 ENV/FR/001512), the Conseil des Vins de Saint-Emilion.

\section{References}

1. A. Parker, I. Garcia de Cortazar Atauri, C. van Leeuwen and I. Chuine. Aust. J. Grape Wine Res., 17, n², 206-216 (2011).

2. C. van Leeuwen, P. Friant, X. Choné, O. Tregoat, S. Koundouras, D. Dubourdieu. Am. J. Enol. Vitic. 55, 207-217 (2004).

3. M. Baggiolini, Rev. Rom. Agr. Vitic. 8:4-6 (1952).

4. C. van Leeuwen, O. Trégoat, X. Choné, B. Bois, D. Pernert and J-P. Gaudillère. J. Int. Sci. Vigne Vin, 43, n³, 121-134 (2009).

5. C. van Leeuwen, Ph. Friant, J-P. Soyer, C. Molot, X. Chone, and D. Dubourdieu. J. Int. Sci. Vigne Vin. 34, $\mathrm{n}^{\circ} 2,75-82$ (2000).
6. J.C. Pinheiro, D.M. Bates, Springer. New York (2000).

7. R. Le Roux, L. de Rességuier, T. Corpetti, N. Jégou, M. Madelin, C. van Leeuwen, H. Quénol, Agricultural and Forest Meteorology, 247, 159-169 (2017).

8. A.J. Winkler, J.A. Cook, W.M. Kliewer, et al., General Viticulture, 2nd ed, University of California Press, 710p (1974).

9. L. de Rességuier, R. Le Roux, H. Quénol and C. van Leeuwen. Proceedings of Climwine, 66-72 (2016). 